\title{
RAPID MAPPING FOR BUILT HERITAGE AT RISK USING LOW-COST AND COTS SENSORS. A TEST IN THE DUOMO VECCHIO OF SAN SEVERINO MARCHE
}

\author{
A. Calantropio ${ }^{\text {a }}$, E. Colucci ${ }^{\text {a }}$, L. Teppati Losè ${ }^{\mathrm{a} *}$ \\ ${ }^{a}$ DAD, Department of Architecture and Design, Politecnico di Torino, Viale Mattioli 39, 10129 Torino, Italy. \\ (alessio.calantropio, elisabetta.colucci, lorenzo.teppati)@polito.it
}

\section{Commission II}

KEY WORDS: Built Heritage, Rapid Mapping, Sensor calibration, 3D model comparison, SfM

\begin{abstract}
:
In the last years, the researchers in the field of Geomatics have focused their attention in the experimentation and validation of new methodologies and techniques, stressing especially the potential of low-cost and COTS (Commercial Off The Shelf) solutions and sensors. In particular, these tools have been used with purposes of rapid mapping in different contexts (ranging from the construction industry, environmental monitoring, mining activities, etc.). The Built Heritage, due to its intrinsic nature of endangered artefact, can largely benefit from the technological and methodological innovations in this research field. The contribute presented in this paper will highlight these main topics: the rapid mapping of the Built Heritage (in particular the one subjected to different types of risk) using low-cost and COTS solutions. Different sensors and techniques were chosen to be evaluated on a specific test site: the Duomo Vecchio of San Severino Marche (MC - Italy), that was partially affected by the earthquake swarm that hit the area of Central Italy starting from the $24^{\text {th }}$ of August 2016. One of the main aims of this work is to demonstrate how low-cost and COTS sensors can contribute to the documentation of the Built Heritage for its safeguard, for damage assessment in case of disastrous events and operations of restoration and preservation.
\end{abstract}

\section{INTRODUCTION}

Among the last researches addresses in Geomatics two key elements can be identify in the field of Rapid Mapping for the Built Heritage: time and sustainability. Often, especially in case of calamitous event, the time dedicated to the operations of survey in the field is restricted due to peculiar conditions (safety of the operator, need of metric data and products in short amount of time, etc.). Moreover, researchers are moving their attention in the direction of the sustainability of approaches and techniques, both from an economical point of view and human resources employed. After a brief overview of the actual state of research in this specific field the work presented will focus on the use of low-cost and COTS (Commercial Off The Shelf) sensors for the generation of 3D models through a SfM (Structure from Motion) approach. First, a comparison between two different products of the Faro CAM2 is presented, to evaluate their use as ground truth indicator and to choose the more sustainable option. Then, different software solutions developed on an image-based approach, both commercial and open source, were tested to analyse the different available outputs. A deeper analysis was also achieved in the attempt to calibrate the different sensors and estimate the differences between the self-calibration performed by the tested photogrammetric software. Finally, some qualitative and quantitative analyses realised on the available products are presented.

\subsection{Rapid Mapping strategies with low-cost and COTS} solutions for the Built Heritage at risk

One of the most accepted definition of Rapid Mapping can be identify in the one provided by the European programme Copernicus (http://emergency.copernicus.eu) that states that Rapid Mapping can be defined as: "on-demand and fast provision (within hours or days) of geospatial information in support of emergency management activities immediately following an emergency event." The traditional Rapid Mapping approaches through the use of satellite data have already proven their efficiency in post disaster scenarios for the creation of large scale maps useful to support the operations in the field (Ajmar et al., 2015; Cooner et al., 2016; De Alwis Pitts and So, 2017; Yamazaki and Liu, 2016). In the context of a multiscale approach, especially for the Rapid Mapping of the Built Heritage, in at risk scenarios is crucial to adopt different strategies to achieve a higher detail of areas of specific interest. For example, the rapid growth in the use of UAVs for aerial photogrammetry is having a big impact also in these scenarios (Boccardo et al., 2015; Chiabrando et al., 2017; Fernandez Galarreta et al., 2015) creating new perspectives for the management of future events and new operation procedures. However, in this work the focus will be set on different types of sensors and considering a different scale (mainly architectural) and the aerial contribution will not be considered in this part of research.Different groups of researchers have already investigated the use of low-cost and COTS sensors in different scenarios (Chiabrando et al., 2017; Das et al., 2015; Kolev et al., 2014; Micheletti et al, 2015), however lot of questions are still open and the definition of operative standards in this field is still missing.

\subsection{The test site: the Duomo Vecchio of San Severino Marche (MC - Italy)}

The site chosen to evaluate the low-cost and COTS sensors is a small portal (Fig.2) of the Duomo Vecchio of San Severino Marche (MC - Italy). The survey campaign conduced in this area is part of the activities of the student team DIRECT (DIsaster RECovery Team of the Politecnico di Torino, in the framework of the task force created after the earthquake swarm in the area of Central Italy. The Team DIRECT is composed by students, with different academic backgrounds (architecture and engineering), involved every year in training activity, both theoretical classes and stages in the field. This project aims to contribute actively to the protection of the Built Heritage and the environmental and architectural assets and it is focused on the heritage vulnerable to natural hazard and risk or subjected to ordinary dangers.

\footnotetext{
* Corresponding author
} 
The Duomo Vecchio (XIII-XV century A.D.) was built on the top of a hill (Monte Nero) located in the Medieval part of the village of San Severino Marche (Fig.1). The current building was erected at the end of the XIII century in the Romanesque-Gothic style; in the fifteenth century a cloister was added, adjacent to the northwest portion of the pre-existing building. The secondary portal, chosen as an architectonic element to test these techniques and methods, overlooks the north-west side of this courtyard. During the centuries, the structures of the site undergone several transformations and renovations; today only the ancient façade and the bell tower are preserved from the first phases of the building history of the complex.

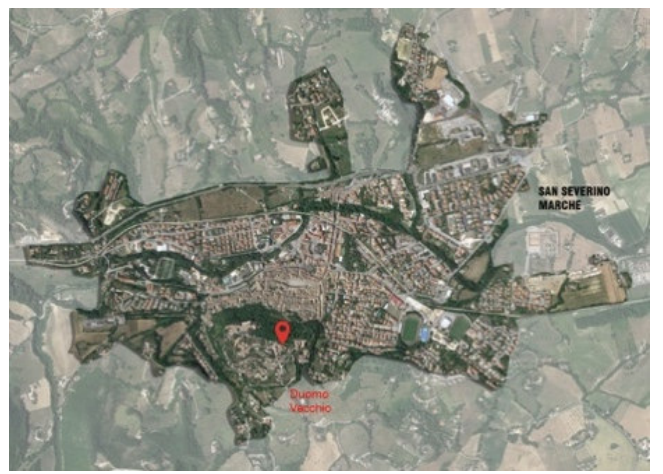

Figure 1. The borders of San Severino Marche

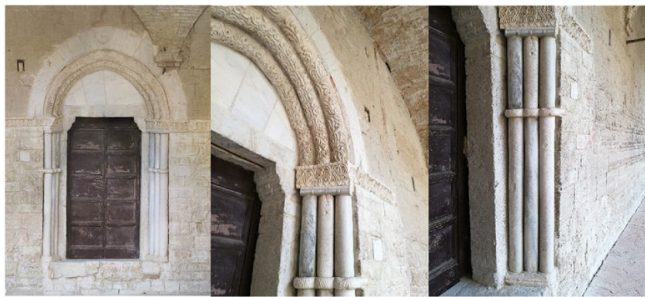

Figure 2. The portal in the cloister of the Duomo Vecchio

\section{TECHNIQUES AND SENSORS}

The acquisitions in the cloister of the Duomo Vecchio were performed in the winter of 2017 during the survey campaign of the Team. The Duomo Vecchio and the adjacent Torre Smeducci were part of a multi-sensors and multi-scale survey that included traditional topographic survey, TLS (Terrestrial Laser Scanner), UAV (Unnamed Aerial Vehicle) photogrammetric acquisitions, CRP (Close Range Photogrammetry), SLAM (Simultaneous Localisation And Mapping) and hand-held scanner acquisitions. For the aim of this research only the acquisition performed with the two laser scanners and the low-cost cameras were considered. The portal was surveyed using five different sensors (Table 1): terrestrial laser scanner, hand-held scanner, a mass market compact camera, smartphone and Steadycam. Due to the emergency conditions in the field it was not possible to realise traditional topographic measurements with the Total Station, the used GCPs were extracted from the LiDAR cloud and used in all the other dataset.

\begin{tabular}{|c|c|c|c|c|}
\hline TLS & $\begin{array}{c}\text { HAND- } \\
\text { HELD } \\
\text { SCAN }\end{array}$ & $\begin{array}{c}\text { COMPACT } \\
\text { CAMERA }\end{array}$ & $\begin{array}{c}\text { SMART } \\
\text { PHONE }\end{array}$ & $\begin{array}{c}\text { STEADY } \\
\text { CAM }\end{array}$ \\
\hline $\begin{array}{c}\text { FARO } \\
\text { FUCUS } \\
120\end{array}$ & $\begin{array}{c}\text { FARO } \\
\text { Freestyle } \\
\text { 3D }\end{array}$ & $\begin{array}{c}\text { Canon } \\
\text { PowerShot } \\
\text { A1100 IS }\end{array}$ & $\begin{array}{c}\text { Huawei } \\
\text { P9 }\end{array}$ & $\begin{array}{c}\text { DJI } \\
\text { OSMO+ }\end{array}$ \\
\hline & 0 & & \\
\hline
\end{tabular}

Table 1. The employed sensors

\subsection{FARO Focus ${ }^{3 D} 120$ and FARO Freestyle3D Scanner}

Two different instruments by Faro CAM2 company were tested on the portal of the Duomo Vecchio: the FARO Focus ${ }^{3 \mathrm{D}} 120$ (TLS) and the Faro Freestyle ${ }^{3 \mathrm{D}}$ (hand-held scanner). The data acquired by these two sensors were compared in order to evaluate the possibilities to use both of them as ground truth element for the further analyses on the imagery sensors.

The TLS acquisition was realised with a laser scanner Focus ${ }^{3 \mathrm{D}}$ Cam2 (http://www.faro.com/en-gb/products/construction-bimcim/faro-focus/ ). The Focus ${ }^{3 \mathrm{D}} 120$ is a terrestrial laser scanner with an action range of $0.6-30 \mathrm{~m}$, a precision of $\pm 2 \mathrm{~mm}$, a vertical field of view of $305^{\circ}$ and a horizontal one of $360^{\circ}$. The following Table 2 report the main parameters used for the acquisition. Concerning the documentation of the portal, three scans were performed, one in front of the architectonic element and the other two on the sides.

\begin{tabular}{|c|c|}
\hline No. acquisitions & 3 \\
\hline Medium no. points/scans & $20^{*} 10^{5}$ \\
\hline Resolution (MPti) & $1 / 4$ \\
& $(1 \mathrm{pt} / 6 \mathrm{~mm}$ at $10 \mathrm{~m})$ \\
\hline Quality & $4 \mathrm{X}$ \\
\hline Scan area & $360^{\circ}$ \\
\hline
\end{tabular}

Table 2. Main parameters used for the laser acquisition

The other sensor used as ground truth for the proposed analyses is the FARO Scanner Freestyle ${ }^{3 \mathrm{D}}$ (http://www.faro.com/itit/prodotti/costruzione-bim-cim/faro-scanner-freestyle3d$\mathrm{x} /$ ?gclid=CJjyzvvc7dYCFUETGwod-9AEHA).

This sensor (main specifications in Table 3) is based on a structured light technology consisting in two infrared cameras that create a "stereo pair" of images looking at the structured light pattern, it offers also a real-time visualization on a mobile device during the acquisition.

The distance between the position of the scanner acquisitions and the portal was around 1.5-2 metres and the data collection time for the 4 scans was around 30 minutes. This scanner was used as a fast and low-cost solution: it maximises the time both during the data acquisition phases on the field and in the post-processing operations.

\begin{tabular}{|l|l|}
\hline Operational range & $0.5-3 \mathrm{~m}$ \\
\hline 3D point accuracy & $<1.5 \mathrm{~mm}$ at $0.5 \mathrm{~m}$ \\
\hline Typical lateral accuracy & $<1 \mathrm{~mm}$ \\
\hline \multirow{3}{*}{ Single image point density } & $\mathrm{Up}$ to 45000 points $/ \mathrm{m}^{2}$ at \\
& $0.5 \mathrm{~m}$ distance \\
& $\mathrm{Up}$ to 10500 points $/ \mathrm{m}^{2}$ at \\
& $1 \mathrm{~m}$ distance \\
\hline Acquisition speed & Up to 88000 points $/ \mathrm{sec}$ \\
\hline
\end{tabular}

Table 3 Specifications of the Faro Freestyle

The data acquired by the TLS were considered as the most reliable due to two main factors: the accuracy of the sensor related to the scale of the surveyed object and the consolidated procedures of its use in the research community. On the other hand, the freestyle is a quite new acquisition and its use still need to be tested and evaluated. A preliminary analysis was achieved on the two models trough the roughness analysis tool implemented in Cloud Compare (http://www.danielgm.net/cc/): the results are reported in Table 4 and Fig. 3. For the reasons mentioned above the TLS was used as reference to evaluate the performances of the hand-held scanner. Another analysis was achieved through the Cloud to Cloud distance tool of CloudCompare: the point cloud of the TLS was set as reference for the one derived from the hand-held scan and the outliners of the two clouds were filtered setting the max distance value at $0.03 \mathrm{~m}$. The results of 
the analysis are showed in Fig.4: 86\% of the points has a distance from the TLS to the freestyle cloud of $\pm 0.004 \mathrm{~m}$. The major deviations from the TLS cloud can be identify in three limited areas: the wooden door, the marble slabs near the decoration of the upper part of the portal and the details of the marble columns on the left and right sides of the doors.

\begin{tabular}{|c|c|c|c|}
\hline \multicolumn{2}{|c|}{} & Focus & Freestyle \\
\hline $\begin{array}{c}\text { Roughness } \\
(\text { dist pt/V.sphere } \\
\mathrm{r}=0.1)\end{array}$ & Gauss mean (m) & 0.009023 & 0.008539 \\
\cline { 2 - 4 } & Gauss std.dev.(m) & 0.008669 & 0.008048 \\
\hline
\end{tabular}

Table 4. Roughness index on portion of the point cloud

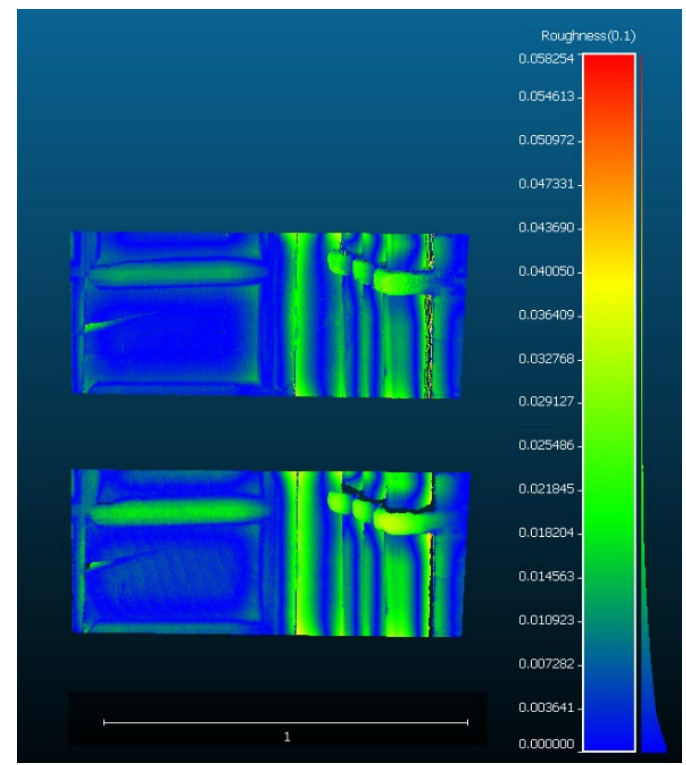

Figure 3. Roughness index maps on the two range-based sensors. TLS (up) and hand-held scanner (down)

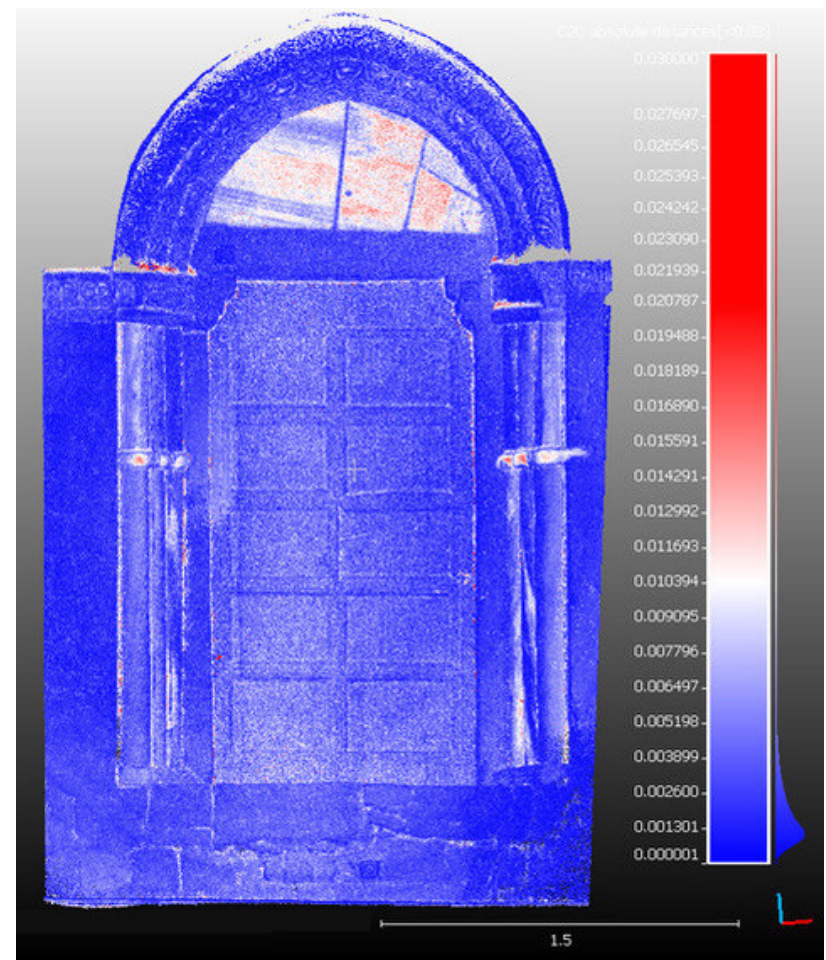

Figure 4. C2C distances analysis performed in CloudCompare

These deviations are the same identified through the preliminary roughness analysis and are justifiable by two main factors: the material proprieties and the geometry of the acquisitions. The wooden door and the marble slab presented a polished surface that doesn't allow the freestyle to work in the best operational environment and the result is a cloud with a higher noise if compared with other type of surfaces. The same factor can be traced in the portions of the cloud relative to the six marble columns. In this case also the geometry of the acquisition should be considered: the lack of information in the columns are also related to the different distances and relative positions of the two sensors. Actually, with the freestyle it was possible in a short amount of time to complete more scan and with a more complex geometry of the acquisition that resulted also in a higher detail of different portions of the cloud.

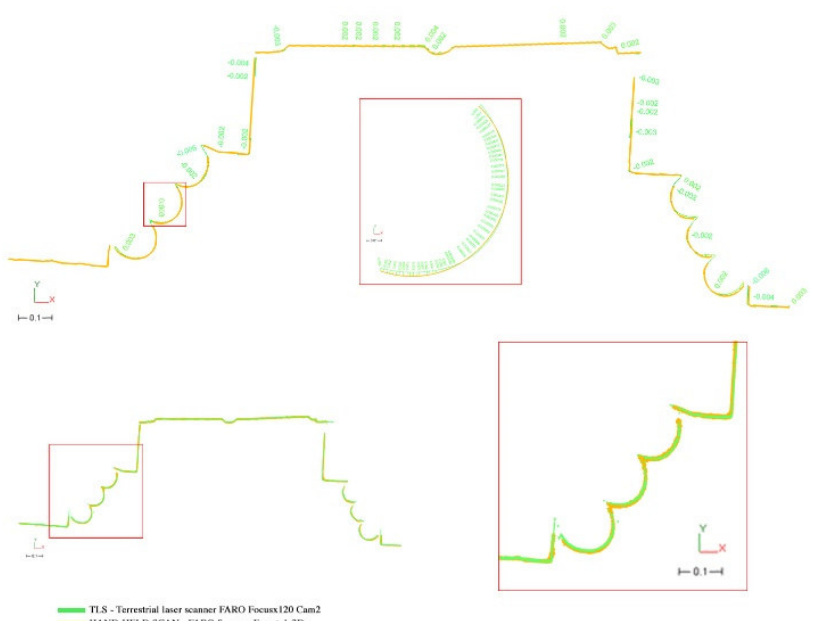

Figure 5. Comparison of different sections automatically extracted from the two point clouds.

Other analyses were also realised through a semi-automatic generation of automatic sections of the different dataset (an example of this type of analyses is reported in Fig.5). These evaluations of sections confirmed the result of the $\mathrm{C} 2 \mathrm{C}$ analyses: the overall deviation between the two model is acceptable and both the sensors were able to provide a model that could be used as ground truth for the analyses on the models generated with an image-based approach. For these reasons the cloud derived from the freestyle was used as ground truth element for the further analyses on the cloud derived from an image-based approach. This was a first preliminary evaluation on the freestyle, further tests will be realised setting up a network of GCPs, measured with topographic traditional methods, to have a more accurate metric control on the acquired data.

\subsection{Image based approach}

Due to the specific interest in testing and analysing new methods that differed for the consolidated Rapid Mapping practices, the second part of this research was oriented towards an image-based approach using three low cost sensors: a compact camera, a COTS Steadycam and a Smartphone (Table 5, 6, 7). The imagebased method not only intends to provide a consistent support for surveying the geometric conditions of the damaged artefacts, but also aims to improve the conditions, in terms of safety and feasibility, under which the metric survey takes place. (Calantropio, 2017). A standard workflow for the acquisitions with these sensors was followed, both acquiring images and videos (the videos were then pre-processed for the extraction of frames to use in the SfM softwares considered). 


\subsubsection{The employed low-cost and COTS sensors}

Canon PowerShot A1100 IS is a compact camera that dated back to the 2009 , it is equipped with a $4 \mathrm{x}$ optical zoom (with optical image stabilizer), $4 \mathrm{x}$ digital zoom, the Digic 4 processor, and a 2.5-inch LCD display with optical viewfinder.

\begin{tabular}{|c|c|}
\hline Model & Canon PowerShot A1100 IS \\
\hline Sensor & $\begin{array}{c}12.1 \mathrm{Megapixel}, \\
\text { CCD 1/2.3” }\end{array}$ \\
\hline Lens & $\begin{array}{c}6.2-24.8 \mathrm{~mm} \mathrm{f} / 2.7-5.6 \\
(35 \mathrm{~mm} \text { film equivalent: } \\
35-140 \mathrm{~mm})\end{array}$ \\
\hline ISO Range & $80-1600$ \\
\hline $\begin{array}{c}\text { Max. Image Size } \\
\text { JPEG, DNG (RAW) }\end{array}$ & $4000 \times 3000 \mathrm{px}$ \\
\hline $\begin{array}{c}\text { Max. Video Resolution } \\
\text { MP4/MOV }\end{array}$ & $640 \times 480(30 \mathrm{fps})$ \\
\hline
\end{tabular}

Table 5 - Specifications of the Canon PowerShot A1100 IS

The Huawei P9 is a top range smartphone that has a technology with a dual camera Leica which allows to capture more light, combining the best colour quality, acquired by the RGB sensor, with the details obtained from the black and white sensor. In the Huawei system a 12MP RGB main sensor is accompanied by a 12MP monochrome chip.

\begin{tabular}{|c|c|}
\hline Model & Huawei P9 \\
\hline Sensor & $\begin{array}{c}\text { Dual Sony IMX 286 } \\
\text { 12 Megapixel }\end{array}$ \\
\hline Lens & $\begin{array}{c}27 \mathrm{~mm} \text { equivalent } \\
\text { focal length } \\
\text { F2.2 aperture }\end{array}$ \\
\hline ISO Range & $50-3200$ \\
\hline Max. Image Size & $4000 \times 3000 \mathrm{px}$ \\
\hline JPEG, DNG(RAW) & $1080 \mathrm{p}(60 \mathrm{fps}))$ \\
\hline $\begin{array}{c}\text { Video Resolution } \\
\text { MP4/MOV }\end{array}$ & \\
\hline
\end{tabular}

Table 6 - Specifications of the Huawei P9

The DJI OSMO+ steadycam is a handheld camcorder manufactured by DJI (Dà-Jiāng Innovations Science and Technology Co.) released in October 2015.

The OSMO+ records $4 \mathrm{~K}$ videos in MP4 or MOV and captures photos at $12 \mathrm{Mpx}(\max 4096 \mathrm{x} 2160 \mathrm{px})$ in Adobe DNG RAW or JPEG formats thanks to a X3/FC350H camera.

The sensor is mounted on a 2-axis gimbal that stabilizes the device, it is an advanced technology designed to acquire video and frame without shakes and movements.

\begin{tabular}{|c|c|}
\hline Model & DJI OSMO+ \\
\hline Sensor & $\begin{array}{c}\text { 1/2.3" CMOS Effective pixels: } \\
12.40 \mathrm{M}\end{array}$ \\
\hline Lens & $94^{\circ} \mathrm{FOV} 20 \mathrm{~mm} \mathrm{f} / 2.8$ \\
\hline ISO Range & $\begin{array}{l}100-3200 \text { (video) } \\
100-1600 \text { (photo) } \\
\end{array}$ \\
\hline $\begin{array}{l}\text { Max. Image Size } \\
\text { JPEG, DNG (RAW) }\end{array}$ & $\begin{array}{c}\text { Shooting: } 4000 \times 3000 \mathrm{px} \\
\text { From 4K video: } 4096 \times 2160 \mathrm{px}\end{array}$ \\
\hline $\begin{array}{l}\text { Video Resolution } \\
\text { MP4/MOV }\end{array}$ & $\begin{array}{c}\text { FHD: } 1920 \times 1080 \\
(24 / 25 / 30 / 48 / 50 / 60 / 100 p)\end{array}$ \\
\hline
\end{tabular}

Table 7 - Specifications of the Steadycam DJI OSMO+

The dataset of images acquired in the field campaign are summarized in the following Table 8 . The images from the Canon and the Huawei were acquired with the traditional workflow (shooting a photo for each chosen positions), while a HQ video were recorded with the DJI Osmo and a set of frames was extracted in a second time. In this first test no radiometric corections were achieved.

\begin{tabular}{|c|c|c|c|}
\hline & $\begin{array}{c}\text { Canon } \\
\text { PowerShot } \\
\text { A1100 IS }\end{array}$ & Huawei P9 & DJI OSMO+ \\
\hline N. images & 30 & 24 & 43 \\
\hline $\begin{array}{c}\text { Acquisition } \\
\text { time }\end{array}$ & $12 \mathrm{~m}$ & $2 \mathrm{~m}$ & $1 \mathrm{~m}$ \\
\hline $\begin{array}{c}\text { Image } \\
\text { resolution }\end{array}$ & $1600 \times 1200$ & $2976 \times 3968$ & $1920 \times 1080$ \\
\hline Focal lenght & $6 \mathrm{~mm}$ & $4 \mathrm{~mm}$ & $4 \mathrm{~mm}$ \\
\hline $\begin{array}{c}\text { Focal 35 mm } \\
\text { equivalent }\end{array}$ & $35 \mathrm{~mm}$ & $27 \mathrm{~mm}$ & $22 \mathrm{~mm}$ \\
\hline
\end{tabular}

Table 8 . The dataset acquired with the three imagery sensors

\section{PROCESSING AND VALIDATION}

\subsection{The open source solution: Mic Mac}

MicMac is a free and open-source photogrammetric suite developed by IGN and ENSG (Deseilligny \& Paparoditis 2006). The operation workflow is similar to the other commercial available solutions but all the commands are sent by the terminal using a simplified command line. For the Tie Points extractions (Tapioca) MicMac use the Vedaldi (Vedaldi, 2007) modified version of the SIFT (Scale Invariant Feature Transform) developed by Lowe (Lowe, 2004). The camera orientation and calibration (Tapas) is the next step; this tool calculates the purely relative orientation of images, using observed tie points as the only input. Unlike the commercial solutions a wide range of camera calibration models are available in MicMac. For this research we have a radial model with 10 degrees of freedom: 1 for focal length, 2 for principal point and distortion center (constrained to have the same value) 3 coefficients of radial distortion $\left(r^{3}, r^{5}, r^{7}\right), 2$ for decentric parameters and 2 for affine parameters.

The next step is carried out using a GUI (Graphical User Interface) for example for the recognition of the GCPs (Ground Control Points) or CPs (Check Points). This step is very costly in terms of operator time. Next are the Bundle Block adjustment and the densification phases.

\subsection{The commercial solution: PhotoScan}

PhotoScan, developed by the Russian company Agisoft LLC and first released in 2010, is a professional software for photogrammetric processing of digital images (Agisoft LLC, 2017) and is a widespread solution in different field of applications due to its simplifyed and automated workflow, it is currently used, for example, for 3D modelling in archaeology (Brutto \& Meli, 2012), as a mapping solution for structural geology and paleoseismology (Bemis et al., 2014), and for forensic documentation applications (Leipner et al., 2016). In order to generate $3 \mathrm{D}$ models using the images previously acquired, the user has to follow a very intuitive workflow, that can be retrieved through a drop-down menu accessible via the upper menu bar.

PhotoScan is capable to estimate internal camera parameters and radial distortion; but only if the images are provided with an EXIF metadata, given the need to know at least the focal length and the pixel size of the employed sensor. In case of lacking these information, it is possible to manually introduce them through the Camera Calibration dialog box. 
In this software it is possible to estimate the following calibration parameters: Focal length in $\mathrm{x}$ - and $\mathrm{y}$-dimensions measured in pixels ( $\mathrm{fx}, \mathrm{fy})$, Principal point coordinates, i.e. coordinates of lens optical axis interception with sensor plane (cx, cy), Skew transformation coefficient, Radial distortion coefficients (k1, k2, $\mathrm{k} 3, \mathrm{k} 4)$ and Tangential distortion coefficients (p1, p2, p3, p4) After aligning the photos trough tie points detection with the first step, the software generates a sparse point cloud. In order to obtain a good quality $3 \mathrm{D}$ model, it is necessary to first compute a dense point cloud; based on the estimated camera positions, the software process depth information for every given camera. Dense cloud can be exported for performing analysis using external tools, or further processed for the generation of textured mesh, tiled model, DEM (Digital Elevation Model) and orthomosaic.

\subsection{Camera Calibrator}

As previously stated, the reflexion on the use of these kind of low-cost and COTS sensors with a photogrammetric approach is still mainly unexplored and operative standard are still missing. One of the aim of this research was to perform a standard and preliminary calibration of the employed sensors, to better understand their performances, especially if compared with the camera parameters given by consolidated software solutions.

To perform the calibration of these sensors the Single Camera Calibrator app of MATLAB was used (MathWorks, 2017). This speditive tool is intended for image processing and computer vision purposes and the aim of the software is to automatically estimate intrinsic, extrinsic, and lens distortion parameters, given a set of 10-20 images of a specific calibration pattern (Figure 6); thus, it can be successfully used for a preliminary estimation of lens distortion parameters for photogrammetric purposes.

The used pattern was created using a CNC (Computer Numerical Control) laser-cutting machine on a wooden table to have a clean and plane surface and with a high precision of the geometric features. It's fundamental to acquire the images of the pattern with a fixed zoom and focus. While the calibration requires at least three images (10-20 are the suggested), we acquired and used around 30 images for each sensor. The images must be acquired with a specific configuration, changing the distance and the orientation between pattern and sensor, to achieve good results (some example of the acquired images and of the processing with Camera Calibrator in Figure 7). The calibration algorithm assumes a pinhole camera model, and after running the applications results and the accuracies of the process are displayed.

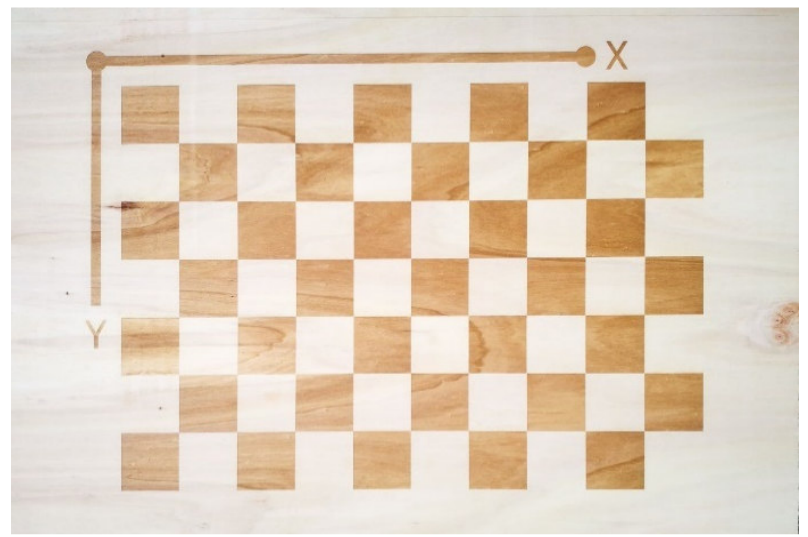

Figure 6. The checkerboard panel with the laser engraved pattern used by the Camera Calibrator app.

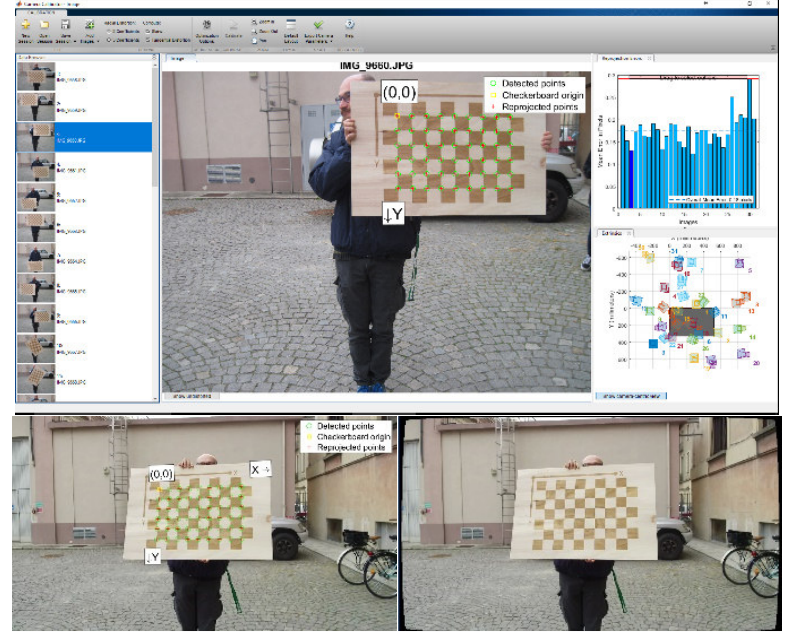

Figure 7. Example of the acquired images (Huawei P9) and the camera calibrator workflow.

\subsection{Comparison of the results: Self-calibration and Camera Calibrator}

Unlike classic camera calibration, the self-calibration performed by photogrammetric softwares does not require any specific pattern in the scene.

The mathematical fundaments behind camera self-calibration were first demonstrated by Olivier Faugeras, Quang-Tuan Luong, and Stephen J. Maybank (Faugeras, et al., 1992).

For the performed self-calibration Photoscan uses Brown's distortion model. In this self-calibration, the parameters are estimated and saved in a readable file format. (Agisoft LLC, 2017). This model estimate radial (K1, K2, K3, K4) and tangential (P1, P2) distortions.

In Mic-Mac is possible to select some camera calibration models, for the objective of the research, was selected the most similar to the Brown's one: FraserBasic (Fraser, 1997). The difference between Fraser (12 degrees of freedom) and FraserBasic is that in the last one the principal point (cx and cy) and the distortion center are constrained to have the same value (so 10 degree of freedom).

In order to evaluate calibration accuracy computed with the above methods, it is necessary to examine the reprojection errors and the camera extrinsics.

Reprojection error is meant as the distance between a point detected from the image and the same point reprojected using the extimated camera parameters.

The camera extrinsics are evaluated observing the relative position of the cameras in the space in relation with the surveyed object, to see if they match our expectations. The following tables $(9,10,11)$ report the calibration parameters for the three imagery sensors evaluated with self-calibration before and after placing GCPs and parameters estimated by MatLab Single Camera Calibrator 


\begin{tabular}{|c|c|c|c|c|c|}
\hline \multicolumn{6}{|c|}{ DJI OSMO+ } \\
\hline & \multicolumn{2}{|c|}{ Before GCPs } & \multicolumn{2}{c|}{ After GCPs } & \multirow{2}{*}{$\begin{array}{c}\text { Camera } \\
\text { Calibrator }\end{array}$} \\
\cline { 2 - 5 } & Ph.Scan & MicMac & Ph.Scan & MicMac & Calin \\
\hline$F$ & 1351.39 & 1346.13 & 1350.86 & 1341.49 & 1358.40 \\
\hline$C x$ & 1.18 & -2.92 & -0.97 & -6.95 & -3.49 \\
\hline$C y$ & -4.74 & -3.96 & -8.24 & -6.45 & -0.14 \\
\hline$B 1$ & 4.41 & $4.85 \mathrm{E}^{-03}$ & -1.15 & $3.93 \mathrm{E}^{-03}$ & $6.95 \mathrm{E}^{-01}$ \\
\hline$B 2$ & 6.00 & $4.02 \mathrm{E}^{-03}$ & $1.29 \mathrm{E}^{+01}$ & $2.09 \mathrm{E}^{-03}$ & - \\
\hline$K 1$ & $8.90 \mathrm{E}^{-02}$ & $4.77 \mathrm{E}^{-08}$ & $1.06 \mathrm{E}^{-01}$ & $6.41 \mathrm{E}^{-08}$ & $1.17 \mathrm{E}^{-01}$ \\
\hline$K 2$ & $-2.52 \mathrm{E}^{-01}$ & $-7.48 \mathrm{E}^{-14}$ & $-3.11 \mathrm{E}^{-01}$ & $-1.43 \mathrm{E}^{-13}$ & $-3.44 \mathrm{E}^{-01}$ \\
\hline$K 3$ & $1.84 \mathrm{E}^{-01}$ & $2.97 \mathrm{E}^{-20}$ & $2.46 \mathrm{E}^{-01}$ & $1.26 \mathrm{E}^{-19}$ & $2.90 \mathrm{E}^{-01}$ \\
\hline$P 1$ & $2.52 \mathrm{E}^{-03}$ & $7.90 \mathrm{E}^{-07}$ & $1.54 \mathrm{E}^{-03}$ & $-1.91 \mathrm{E}^{-08}$ & $-1.65 \mathrm{E}^{-03}$ \\
\hline$P 2$ & $-3.70 \mathrm{E}^{-04}$ & $2.12 \mathrm{E}^{-07}$ & $-1.48 \mathrm{E}^{-03}$ & $2.96 \mathrm{E}^{-07}$ & $7.84 \mathrm{E}^{-05}$ \\
\hline
\end{tabular}

Table 9. Calibration parameters for the DJI OSMO+ evaluated with self-calibration before and after placing GCPs and parameters estimated by MatLab Single Camera Calibrator

\begin{tabular}{|c|c|c|c|c|c|}
\hline \multicolumn{5}{|c|}{ CANON POWERSHOT A1100 IS } \\
\hline & \multicolumn{2}{|c|}{ Before GCPs } & \multicolumn{2}{|c|}{ After GCPs } & \multirow{2}{*}{$\begin{array}{c}\text { Camera } \\
\text { Calibrator }\end{array}$} \\
\cline { 2 - 5 } & Ph.Scan & MicMac & Ph.Scan & MicMac & \\
\hline$F$ & 1629.14 & 1624.86 & 1629.49 & 1624.54 & 1618.24 \\
\hline$C x$ & 28.03 & 18.29 & 26.71 & -36.59 & 8.87 \\
\hline$C y$ & -8.40 & -19.65 & -29.56 & -21.61 & -9.81 \\
\hline$B 1$ & -2.48 & $-2.79 \mathrm{E}^{-03}$ & -4.34 & $-1.80 \mathrm{E}^{-03}$ & 1.47 \\
\hline$B 2$ & -1.98 & $-1.96 \mathrm{E}^{-03}$ & -5.61 & $1.69 \mathrm{E}^{-03}$ & - \\
\hline$K 1$ & $-1.34 \mathrm{E}^{-01}$ & $-4.98 \mathrm{E}^{-08}$ & $-1.33 \mathrm{E}^{-01}$ & $-4.63 \mathrm{E}^{-08}$ & $-1.38^{-01}$ \\
\hline$K 2$ & $7.59 \mathrm{E}^{-02}$ & $9.45 \mathrm{E}^{-15}$ & $8.33 \mathrm{E}^{-02}$ & $-9.95 \mathrm{E}^{-15}$ & $-1.61 \mathrm{E}^{-02}$ \\
\hline$K 3$ & $-1.53 \mathrm{E}^{-02}$ & $-1.78 \mathrm{E}^{-22}$ & $-3.37 \mathrm{E}^{-02}$ & $2.96 \mathrm{E}^{-22}$ & $1.40 \mathrm{E}^{-01}$ \\
\hline$P 1$ & $1.07 \mathrm{E}^{-03}$ & $4.40 \mathrm{E}^{-07}$ & $9.60 \mathrm{E}^{-04}$ & $-1.89 \mathrm{E}^{-06}$ & $-4.34 \mathrm{E}^{-04}$ \\
\hline$P 2$ & $1.28 \mathrm{E}^{-04}$ & $-3.23 \mathrm{E}^{-07}$ & $-1.34 \mathrm{E}^{-03}$ & $-3.91 \mathrm{E}^{-07}$ & $4.73 \mathrm{E}^{-04}$ \\
\hline
\end{tabular}

Table 10. Calibration parameters for the Canon compact camera evaluated with self-calibration before and after placing GCPs and parameters estimated by MatLab Single Camera Calibrator

\begin{tabular}{|c|c|c|c|c|c|}
\hline \multicolumn{6}{|c|}{ HUAWEI P9 } \\
\hline & \multicolumn{2}{|c|}{ Before GCPs } & \multicolumn{2}{c|}{ After GCPs } & \multirow{2}{*}{$\begin{array}{c}\text { Camera } \\
\text { Calibrator }\end{array}$} \\
\cline { 2 - 5 } & Ph.Scan & MicMac & Ph.Scan & MicMac & \\
\hline$F$ & 3093.61 & 3093.47 & 3098.27 & - & 3069.86 \\
\hline$C x$ & -4.17 & -0.12 & -6.03 & - & -20.28 \\
\hline$C y$ & -8.18 & -1.65 & -5.27 & - & -34.26 \\
\hline$B 1$ & 2.73 & $3.28 \mathrm{E}^{-03}$ & $-1.02 \mathrm{E}^{-01}$ & - & 1.83 \\
\hline$B 2$ & $2.33 \mathrm{E}^{-01}$ & $1.48 \mathrm{E}^{-03}$ & $-9.94 \mathrm{E}^{-01}$ & - & - \\
\hline$K 1$ & $8.59 \mathrm{E}^{-02}$ & $8.20 \mathrm{E}^{-09}$ & $9.54 \mathrm{E}^{-02}$ & - & $-1.42 \mathrm{E}^{-01}$ \\
\hline$K 2$ & $-4.01 \mathrm{E}^{-01}$ & $-3.79 \mathrm{E}^{-15}$ & $-4.42 \mathrm{E}^{-01}$ & - & $3.40 \mathrm{E}^{-01}$ \\
\hline$K 3$ & $5.33 \mathrm{E}^{-01}$ & $4.94 \mathrm{E}^{-22}$ & $5.88 \mathrm{E}^{-01}$ & - & $-2.93 \mathrm{E}^{-01}$ \\
\hline$P 1$ & $4.44 \mathrm{E}^{-04}$ & $3.72 \mathrm{E}^{-07}$ & $2.53 \mathrm{E}^{-04}$ & - & $-2.19 \mathrm{E}^{-03}$ \\
\hline$P 2$ & $-6.40 \mathrm{E}^{-04}$ & $-4.99 \mathrm{E}^{-08}$ & $-5.76 \mathrm{E}^{-04}$ & - & $-1.22 \mathrm{E}^{-03}$ \\
\hline
\end{tabular}

Table 11. Calibration parameters for the Huawei smartphone evaluated with self-calibration before and after placing GCPs and parameters estimated by MatLab Single Camera Calibrator
Unfortunately, it was not possible to complete the estimation of the smartphone's camera parameters (Huawei P9) with MicMac after placing the GCPs; the reason of this issue is still under investigation. One of the possibilities it's related with the geometry of the object and its acquisition; the error reported in MicMac was: "Distortion Inversion by finite difference do not converge". To overcome this issue, we tried to generate a better sparse cloud (Tapioca step). Nevertheless, it failed again.

Moreover, the used calibration model in MicMac (FraserBasic) despite very similar to the Brown's one (same number of degrees of freedom) expresses the $\mathrm{B}, \mathrm{K}$ and $\mathrm{P}$ parameters using a very different order of magnitude. For the above reason it was not possible to compute an alignment with MicMac using the distortion parameters provided by MatLab Camera Calibrator. It will be necessary to better understand the behaviour of the software in this regard and to perform further tests.

These themes will be further examined in the forthcoming researches. For all these reasons and in the framework of this research it was decided to achieve a deeper analysis on the available products derived from Photoscan. Some other considerations on the camera calibration parameters will be further discuss in the section 5 .

\section{PRODUCTS EVALUATION}

The analyses and considerations that will be presented in this section are resulting from the model generated importing the camera calibration parameters derived from MATLAB in Photoscan. The $\mathrm{C} 2 \mathrm{C}$ analyses realised in CloudCompare (using the freestyle cloud as ground truth element) are reported in Figure 8. These analyses show that in all the three compared models around the $80 \%$ of points is included between 0 and $0,007 \mathrm{~m}$, confirming the good result achievable using these low-cost sensors. For the steadycam the major deviations can be identify in the decorative part (especially on the column and in the upper frieze): these anomalies could be caused by the geometry and modalities of the acquisition. The sensor was used in video mode (with a partial reduction of the final images quality) and with an irregular geometry of acquisition. Concerning the other two sensors the deviations are concentred on the lower part of the columns and on the threshold. Also in these cases an important role was played by the acquisition phase, probably the overlap between images and the camera positions projected on the field were not sufficient. All the considered factors demonstrate the importance of defining standard procedures of use for this kind of sensors.

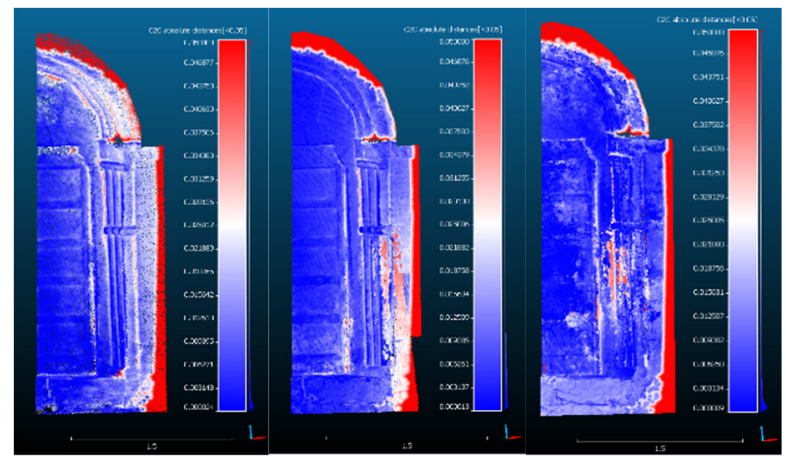

Figure $8 . \mathrm{C} 2 \mathrm{C}$ analyses between the freestyle 3D model and the three considered imagery sensors models (from left: Steadycam, Compact camera, smartphone) 
Moreover, some qualitative analyses were carried out on another kind of products: the orthophotos.

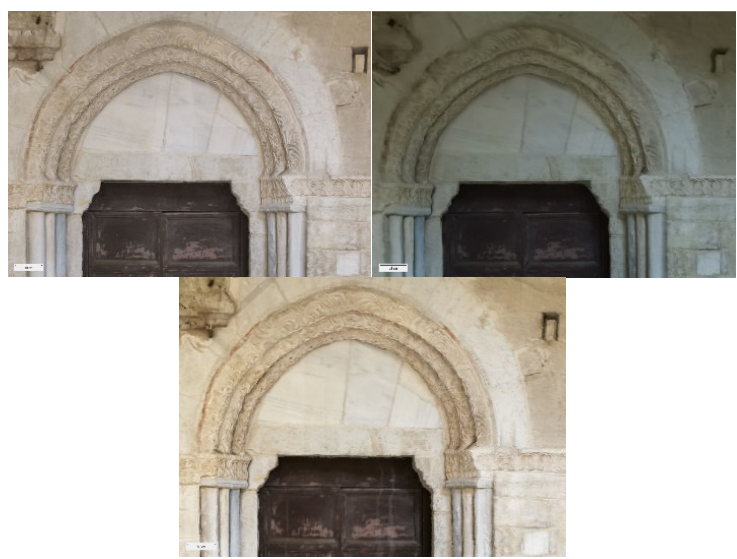

Figure 9. Portions of the orthophotos extracted from the three sensors (left: Compact camera, right: Steadycam, bottom: smartphone)

The first consideration on these products is related with the high distortion localised on the upper portion of the decorated portal. This factor can be related with the high radial distortion close to the edges of the sensors. In fact, during the acquisition phase the above-mentioned part of the arch was almost every time captured close to the edges. Also, the radiometric information is really different in the three orthoimages. Considering that the three acquisitions were realised almost contemporary its mandatory to underline the different behaviour of the three sensors related to the recording of the radiometric features of the surveyed object.

\section{DISCUSSION AND CONCLUSION}

The first consideration emerged from this work is related with the possibilities to use a hand-held scanner to replace, in specific condition, the TLS solution. The Faro Freestyle, for small architectural elements (portal, columns, capitals, decorative details) or small/medium objects can be considered an excellent solution (Di Pietra et al, 2017). In a high or medium risk scenario its light weight, small dimensions and short time of acquisition are interesting features. However, it's crucial to consider also some critical factors: the type of material could be really challenging and also the dimensions of the artefact to survey is limited (small architectural elements, objects, statues, etc.). Also, the user should be aware that in specific condition the point cloud present a marked noise and the time of post-processing operation should be also considered.

The calibration of the three sensors produced some confirmations and some critical issues that need to be further investigated. The main achievement could be traced in the comparison between the parameters extracted from the self-calibration of the photogrammetric software and the camera calibrator tool. The first issue could be traced in the use of the open source solution Mic Mac: the parameters obtained from the self-calibration using the Fraser basic model are not comparable with the ones of the Photoscan self-calibration and of the MATLAB tool. As is possible to notice in the Tables 9,10 and 11 the only consistent values are the ones related to the focal length and the coordinates of the principal point. In Photoscan, the self-calibration performed with the Brown's model returned values that are comparable with the ones of MATLAB. We can thus say that the calibration models its already well implemented in Photoscan for these kind of low-cost and COTS sensors, and the returned parameters are confirmed by the process of calibration performed in MATLAB. The critical features present in MicMac can be attributed to the model used for the self-calibration: the Fraser basic is probably not well implemented yet to manage the parameters of these sensors.

One of the aim of the future researches will be to focus again on the opensource solution and to better understand and implement the critical features emerged in this preliminary work. Secondly it is really necessary to define some strong and reliable standard operational practices for the fieldwork and the data acquisition phases. Moreover, more robust methods for the camera calibration need to be investigated and tested to refine the preliminary results achieved in this research, especially using GCPs (measured with traditional topographic techniques) to guarantee more controllable results. Finally, a synthetic graphic overview of the many factors involved in a global evaluation of operational efficiency in use and metric accuracy of results about the tested low-cost and COTS sensors is given in the Table 12 reported at the end of the paper, after the references.

\section{ACKNOWLEDGEMENTS (OPTIONAL)}

Authors would like to express their gratefulness to DIRECT team members and tutors. Thanks to the MOD Lab Arch of Politecnico di Torino in Valentino Castle. Thanks to the operative task force of Politecnico di Torino for the financial and logistic support of the missions in the area of Central Italy.

\section{REFERENCES}

Agisoft LLC. (2017, 10 14). Agisoft PhotoScan. Retrieved from http://www.agisoft.com/

Ajmar, A., Boccardo, P., Disabato, F., and Giulio Tonolo, F., 2015. Rapid Mapping: geomatics role and research opportunities. In: Rendiconti Lincei, 26(S1), 63-73. https://doi.org/10.1007/s12210-015-0410-9

Bemis, S. P., Micklethwaite, S., Turner, D., James, M. R., Akciz, S., Thiele, S. T., and Bangash, H. A., 2014. Ground-based and UAV-based photogrammetry: A multi-scale, high-resolution mapping tool for structural geology and paleoseismology. In: Journal of Structural Geology, 69, 163-178.

Boccardo, P., Chiabrando, F., Dutto, F., Tonolo, F., and Lingua, A., 2015. UAV Deployment Exercise for Mapping Purposes: Evaluation of Emergency Response Applications. In: Sensors, 15(7), 15717-15737. https://doi.org/10.3390/s150715717

Brutto, M. L., and Meli, P., 2012. Computer vision tools for 3D modelling in archaeology. In: International Journal of Heritage in the Digital Era, 1(1_suppl), 1-6.

Calantropio, A., 2017. Drones application for safety in construction sites and in technical measures for seismic emergency response. (pp. 174-190). MA thesis, Torino: Politecnico di Torino.

Chiabrando, F., Sammartano, G., and Spanò, A., 2017. A comparison among different optimization levels in 3D multisensor models. A test case in emergency context: 2016 Italian earthquake. In: International Archives of the Photogrammetry, Remote Sensing and Spatial Information Sciences, XLII-2/W3, 155-162. https://doi.org/10.5194/isprs-archives-XLII-2-W3- 


\section{$155-2017$}

Cooner, A., Shao, Y., \& Campbell, J., 2016. Detection of Urban Damage Using Remote Sensing and Machine Learning Algorithms: Revisiting the 2010 Haiti Earthquake. In: Remote Sensing, 8(10), 868. https://doi.org/10.3390/rs8100868

Das, J., Cross, G., Qu, C., Makineni, A., Tokekar, P., Mulgaonkar, Y., and Kumar, V., 2015. Devices, systems, and methods for automated monitoring enabling precision agriculture. In: 2015 IEEE International Conference on Automation Science and Engineering (CASE) (pp. 462-469). IEEE. https://doi.org/10.1109/CoASE.2015.7294123

De Alwis Pitts, D. A., and So, E., 2017. Enhanced change detection index for disaster response, recovery assessment and monitoring of accessibility and open spaces (camp sites). In: International Journal of Applied Earth Observations and Geoinformation, 57,

https://doi.org/10.1016/j.jag.2016.12.004

Di Pietra, V., Donadio, E., Picchi, D., Sambuelli, L., and Spanò, A., 2017. Multi-Source 3d Models Supporting Ultrasonic Test to Investigate an Egyptian Sculpture of the Archaeological Museum in Bologna. IN: International Archives of the Photogrammetry, Remote Sensing and Spatial Information Sciences, 42, 259-266.

Faugeras, O. D., Luong, Q. T., and Maybank, S. J., 1992. Camera self-calibration: Theory and experiments. In: European conference on computer vision (pp. 321-334). Springer, Berlin, Heidelberg.

Fernandez Galarreta, J., Kerle, N., and Gerke, M., 2015. UAVbased urban structural damage assessment using object-based image analysis and semantic reasoning. In: Nat. Hazards Earth Syst. Sci, 15, 1087-1101. https://doi.org/10.5194/nhess-15-10872015

Fraser, C., 1997, Digital camera self-calibration, In: ISPRS Journal of Photogrammetry and Remote Sensing, vol. 52, issue 4, pp. 149-159.
Kolev, K., Tanskanen, P., Speciale, P., and Pollefeys, M., 2014. Turning Mobile Phones into 3D Scanners. In: 2014 IEEE Conference on Computer Vision and Pattern Recognition (pp. 3946-3953). IEEE. https://doi.org/10.1109/CVPR.2014.504

Leipner, A., Baumeister, R., Thali, M. J., Braun, M., Dobler, E., and Ebert, L. C., 2016. Multi-camera system for 3D forensic documentation. In: Forensic science international, 261, 123-128.

Lowe, D. G., 2004. Distinctive image features from scaleinvariant keypoints. In: International journal of computer vision, 60(2), pp.91-110.

Micheletti, N., Chandler, J. H., and Lane, S. N., 2015. Investigating the geomorphological potential of freely available and accessible structure-from-motion photogrammetry using a smartphone. In: Earth Surface Processes and Landforms, 40(4), 473-486. https://doi.org/10.1002/esp.3648

Nocerino, E., Lago, F., Morabito, D., Remondino, F., Porzi, L., Poiesi, F., Eisert, P., 2017. A smartphone-based 3D pipeline for the creative industry - The Replicate EU project. In: International Archives of the Photogrammetry, Remote Sensing and Spatial Information Sciences, 535-541. https://doi.org/10.5194/isprs-archives-XLII-2-W3-535-2017

Pierrot-Deseilligny and M., Paparoditis, N., 2006. A multiresolution and optimization-based image matching approach: An application to surface reconstruction from spot5hrs stereo imagery. In: Archives of Photogrammetry, Remote Sensing and Spatial Information Sciences 36, Vol. 1/W41.

Vedaldi, A., 2007. An open implementation of the SIFT detector and descriptor, A., UCLA CSD.

Yamazaki, F., \& Liu, W. (2016). Remote sensing technologies for post - earthquake damage assessment : a case study on the 2016 Kumamoto earthquake. In: Th ASIA Conference on Earthquake Engineering, 22-24.

\begin{tabular}{|c|c|c|c|c|c|c|c|c|}
\hline & \multirow[b]{2}{*}{ Price } & \multicolumn{3}{|c|}{ Acquisition } & \multicolumn{4}{|c|}{ Processing } \\
\hline & & Autonomy & Acquisition time & $\begin{array}{c}\text { Operator } \\
\text { work }\end{array}$ & $\begin{array}{l}\text { Hardware } \\
\text { work }\end{array}$ & User Work & $\begin{array}{c}\text { Processing } \\
\text { time }\end{array}$ & Detail \\
\hline $\begin{array}{c}\text { FARO } \\
\text { FUCUS }^{\mathrm{x}} \\
120\end{array}$ & 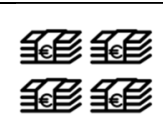 & 同 & 可 员 & & Fo: & & 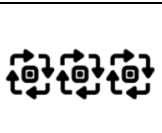 & 星渄渄渄 \\
\hline $\begin{array}{c}\text { FARO } \\
\text { Freestyle } \\
\text { 3D }\end{array}$ & 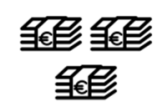 & & 묘용 & & 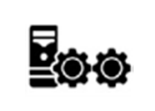 & & 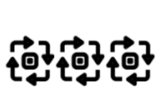 & \\
\hline $\begin{array}{c}\text { Canon } \\
\text { PowerSh } \\
\text { ot A1100 } \\
\text { IS }\end{array}$ & 酉影 & & 묘 & 党 & Oరం: & & 祻祻 & \\
\hline $\begin{array}{c}\text { Huawei } \\
\text { P9 }\end{array}$ & 西影酉影 & 闹占 & 묭 & $\frac{\omega}{3}$ & 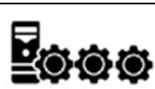 & & 尌祻 & P梀 \\
\hline $\begin{array}{c}\text { DJI } \\
\text { OSMO+ }\end{array}$ & 具影军影 & 问 & 묘 & & 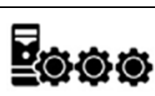 & & 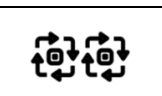 & 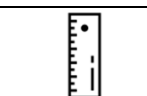 \\
\hline
\end{tabular}

Table 12. Synthetic graphic overview of the many factors involved in a global evaluation of operational efficiency in use and metric accuracy of results about the tested low-cost and COTS sensors. 